Review Essay

\title{
(Un)realistic utopia: Rethinking political legitimacy, democracy, and resistance in China
}

Contemporary Political Theory (2021) 20, S60-S66. https://doi.org/10.1057/s41296020-00423-3; published online 10 July 2020

\section{Democracy in China: The Coming Crisis}

Jiwei $\mathrm{Ci}$

Harvard University Press, Cambridge, 2019 x + 420 pp., ISBN: 9780674238183

The Politics of People: Protest Cultures in China

Shih-Ding Liu

State University of New York Press, Albany, 2019, xiv + 234 pp., ISBN: 9781438476216

The rise of China as the second largest economy and a stable authoritarian regime has led political theorists to emphasize the importance of performance in the evaluation of regime legitimacy. Due to its ability to get things done efficiently and to induce rapid economic growth, China is also increasingly perceived as an alternative to the Western liberal democratic model of legitimation. The uncomfortable fact that ostensibly stable democracies are unable to defend themselves against right-wing populism has contributed to the loss of liberal democracy's appeal. Thus, advocates of China's model of legitimation such as Daniel Bell (2015, p. 3) argue that the Chinese authoritarian system is a political meritocracy in which political leaders 'take a long-term view rather than cater to electoral cycles' and that the system can 'prevent the exercise of power by shortterm-minded "populist" political leaders.' In other words, advocates suggest that China represents a better regime in which legitimacy is gained non-democratically and thus can avoid the negative consequences associated with democratic election.

The two books under review challenge two widely shared assumptions held by advocates of the China model: (1) that China represents a distinctive model of legitimation, and (2) that China is a stable authoritarian regime. Jiwei Ci draws our attention to the unavoidable legitimacy crisis that the Chinese Communist Party $(\mathrm{CCP})$, as the only real party in a one-party authoritarian regime, will eventually need to confront. He aims to show that 'grave consequences will follow if China does not democratize and do so with well-conceived and well-executed preparation' (p. 16). In the same vein, Shih-Ding Liu shows that, despite the oppressive

(c) 2020 Springer Nature Limited. 1470-8914 Contemporary Political Theory Vol. 20, S2, S60-S66 www.palgrave.com/journals 
political structure in China, people exercise their agency through creative resistance that exploits the legal grey zones and internal contradictions of the authoritarian regime (pp. 8-9). An oppressive political structure does not necessarily strengthen the stability of the regime; rather, it invites people to resist the regime creatively in ways that the regime cannot anticipate in advance.

In Democracy in China, $\mathrm{Ci}$ advances three central claims. First of all, the China model is not a distinctive model of legitimation, and performance legitimacy alone does not fully address the issue of political legitimacy (p. 19). Second, the only suitable form of political governance for China is democracy because China is already a democratic society (pp. 20-21). Third, the best way to make the case for democracy in China is "not chiefly normative, as such arguments usually are, but essentially prudential' (p. 9). The prudential case for democracy in China addresses the practical benefits of democracy for the CCP's regime stability and continued governance.

$\mathrm{Ci}$ insightfully points out that current debates on regime legitimation mistakenly take performance as a stand-alone condition of legitimacy. He argues that performance alone does not answer the question of why the CCP, and only the CCP, has the right to rule in the first place (p. 44). According to the CCP's selfunderstanding, this right to rule derives from the communist revolutionary legacy (p. 41) - the party and its leaders were agents who brought the new China into being. Thus, 'performance legitimacy is not really legitimacy in the sense of the right to rule,' as the latter 'involves the comprehensive exercise of power well beyond mere performance and governance' (p. 49). Nonetheless, if legitimacy comes from the revolutionary legacy, $\mathrm{Ci}$ argues, $\mathrm{Xi}$ Jinping would be among the last generation of leaders in the CCP who can still gain legitimacy through such legacy, because it is 'the last [generation] still able to help themselves substantially to the revolutionary spirit for purposes of legitimacy' (p. 90). Against this backdrop, $\mathrm{Ci}$ argues that performance success does not 'contribute strictly to legitimacy but rather that such success helps ameliorate a lack of legitimacy' resulting from the fading memory of the communist revolution (p. 52). Thus, Ci convincingly shows that there is no distinctive Chinese model of political legitimacy in the sense of the authorization of the right to rule. Extraordinary performance in economic development only helps to postpone the legitimacy crisis, but does not solve it.

The more provocative claim $\mathrm{Ci}$ advances is what he calls the 'fittingness argument' for democracy (p. 117). Probably very few political scientists or political theorists would suggest that China is a democratic country. Nonetheless, following Tocqueville, $\mathrm{Ci}$ argues that we need to distinguish democratic political institutions from democratic society, and he claims that China is already a democratic society even though it is politically undemocratic. According to $\mathrm{Ci}$, China is a democratic social state for three reasons. Economically, for the past four decades, reforms have separated the economic from the political domain, and an independent economic 
domain 'clearly reduces both the need and the justification for a nondemocratic form of government' (p. 110). Ideologically, there is an 'increasingly sizable middle class naturally ... drawn to broadly liberal and (bourgeois) egalitarian values.' Meanwhile there is also 'a growing entrepreneurial class with an even greater ... reluctance to defer to unelected political power' (p. 110). Socially, since Mao, fixed social hierarchies have been demolished. Citizens in China increasingly see themselves as formally equal, deserving of equal treatment and status, and the CCP now sees its mission as furthering publicly defined conceptions of happiness. In other words, 'the party no longer sees itself as pursuing the lofty goal of a far-off communism and leading the populace in this pursuit,' but submits to the people's own understanding of the goals of politics (p. 112). The fittingness argument suggests that the only 'fitting' political system for a democratic social state is democracy. Unless the political system fits the democratic social state, society will become increasingly ungovernable.

$\mathrm{Ci}$ sees no turning point for the democratic social state in China. Hence the prudential case for democracy is that, given the fact of the democratic social state, the CCP ought to gradually democratize China by giving people more political freedom, building a more solid civil society, and cultivating the political capacities of the people if it wants to avoid a crisis of legitimacy that would undermine the party's governing capacity and the stability of the regime. $\mathrm{Ci}$ calls his proposal a 'realistic utopia' because, he believes, the prudential case for democracy would be easier for the CCP to accept than the normative case, while also bringing about normatively desirable consequences (p. 253).

Despite the insights and admirable motivations of Ci's proposal, the prudential case, however, is essentially self-contradictory. A core assumption underpinning Ci's prudential framing is that the CCP is the 'de facto dominant force' (p. 254), and without the CCP's consent, the transition to a democratic China is impossible. The question is why, if the CCP is extremely powerful, it would agree with a democratic reform that paves the way to its own grave? $\mathrm{Ci}$ assumes that the party might not be able to handle increasing political resistance, but he ignores the fact that the CCP is a learning organization that is willing to absorb new knowledge and techniques of political oppression (Lee and Zhang, 2013, pp. 1503-1504). For instance, modern surveillance technologies have given the party unprecedented disciplinary power, such as the social credit system, to punish disobedient subjects. In the absence of an empirical analysis of the party's oppressive capacities, Ci's assumption appears to be a rather shaky foundation to ground the claim that the party needs democracy to solve the coming crisis of legitimacy.

$\mathrm{Ci}$ is not entirely unaware of this tension. A common contemporary understanding of democracy rests on a combination of free and fair elections and party rotation. Thus, for a state to be politically democratic, there should be more than one party, and the opposition party must have a real chance of winning elections. But the possibility of losing its ruling status might discourage the CCP 
from initiating democratic reforms. Ci resolves this tension by equivocating on the meaning of political democracy. He argues that as long as the regime satisfies some standards of 'publicness, representativeness, and consent,' 'it is advisable to leave the form of government, as well as the manner of choosing it, open.' Moreover, western liberal democracy is not 'the only genuine form or method of democracy' (p. 268). On this view, political democracy in China is not inherently incompatible with the kind of one-party system that China currently is.

Ci's realistic utopia, therefore, is neither realistic nor utopian. It is unrealistic, because the prudential case for democracy will not convince an authoritarian party with the capacity to suppress political resistance on a massive scale to set up a system that drains it of its power. It is not utopian, because in order to persuade the party of the potential benefits of democracy, the notion of democracy has been stretched to include obviously undemocratic forms of government. Therefore, Ci's proposal will please neither the party nor democratic activists. This is particularly relevant, given Ci's suggestion that democratic activists exercise 'political restraint' and fight for democracy 'without undermining the authority of the CCP' (p. 369). But it is the CCP who determines what undermines its authority. Thus, Ci's suggestion amounts to the claim that democratic activists in China abstain from democratic action of which the CCP disapproves. This sets an impossible and unreasonably demanding standard for a democratic movement. In Ci's realistic utopia, democratic activists must be patient and must demand that the CCP fulfill the democratic rights guaranteed by the constitution in such a way as to avoid being perceived as challenging the CCP's authority. In other words, he demands the kind of patience and restraint that many of the activists have exhibited, without significant gains in democratic development, since the protests in 1989.

Liu's The Politics of People shares Ci's view that China is not as stable as advocates of the China model suggest. But whereas $\mathrm{Ci}$ emphasizes the necessity of concession that democratic activists must make due to the immense oppressive power of the CCP, Liu stresses Partha Chatterjee's (2004) idea of the 'politics of the governed' to suggest that, despite the oppressive political structure and gradually depleting political resources for making claims in China, activists can still creatively employ different strategies for collective claim-making. By combining Judith Butler's (2015) idea of the 'performativity of political practices' and Chatterjee's 'politics of the governed,' Liu aims to show that 'people express their dissent by and through performances of collective discontent' (p. 3) that takes many different forms. Thus, Liu suggests that 'the nature and outcome of political struggles cannot be presupposed and predetermined,' because they are 'brought into being by contexts and their practices' (p. 17). Rather than observing political resistance from a macro-perspective, Liu's work examines the agency of people from a micro-perspective by engaging their contentious practices.

Liu highlights the agency of people in three central cases: the political use of the body, strategic engagement with the state, and cultural resistance exemplified in

(c) 2020 Springer Nature Limited. 1470-8914 Contemporary Political Theory $\quad$ Vol. 20, S2, S60-S66 S63 
artistic production and cyberpolitics. Together, these three cases illustrate Chinese protest cultures that arise from specific oppressive conditions under the Chinese regime.

In the political use of the body, people 'utilize their bodies to negotiate with state authorities,' and 'the body is deployed as a medium of resistance and struggle' in order to increase the visibility of dissent (p. 24). An example is protesting by walking collectively in silence. In China, a legal mass demonstration must be approved by the public security department. Thus, in the 2007 Xiamen anti-PX protest, citizens collectively took to the street, walking together, rather than demonstrating, to forestall government repression (p. 33). Walking together not only 'reduced the sense of fear among participants' but also made it impossible for the police to intervene as they 'cannot clearly distinguish demonstrators from "onlookers", (pp. 33-34). Examples of the creative deployment of the body for political resistance abound. In 2013, a group of workers in Shannxi Province knelt down before a public square to urge 'the government to do justice for the people' (p. 37). Kneeling down collectively has cultural meaning in China and expresses 'frustration, humbleness, [and] sadness' that can 'trigger moral sympathy and compassion' (p. 37). Kneeling down collectively in a public space, therefore, is a strategic deployment of the body that appropriates the cultural meaning of a bodily act to attract public concern and sympathy so as to raise the political cost of suppression. Other cases of the political use of the body involve naked protest, suicidal protest, the deployment of funeral symbols, or unapproved collective mourning. As Liu suggests, the body is a political resource that everyone has, and in a state 'that largely lacks channels to voice grievances, bodies are a crucial resource ... to make themselves and their grievances visible' (p. 53).

Another peculiar feature of China's protest cultures that Liu highlights is 'protestors' engagement with the state in the process of configuring performative politics' (p. 87). Instead of directly targeting the central government, protests in China are usually framed under the 'imagery of "evil local cadres vs. benevolent center"' (p. 90). As local governments are directly responsible for the implementation of policy, they have 'increasingly become the prime target of discontent' (p. 90). In the 2011 Wukan Revolt, famers who protested against the local government's land dispossession policy raised 'the national flag ... over the occupied site' to express their loyalty to the central government and the patriotic sentiment of the movement in order to avoid state-level crackdown (p. 104). Exploring contradictions within various levels of government to protest against local government misbehaviors is common in China, and a central characteristic of most of these protests is the 'alliance with the center' (p. 89).

The creativity and agency of protesters, Liu suggests, are also exemplified in their 'spectacular audio-visual performances': the 'aestheticization of protest' is 'the creative production and display of cultural symbols' for connecting and mobilizing potential participants (p. 143). These artworks perform a number of 
functions, including increasing visibility of protest claims, grabbing attention, and reconstituting sensory experience. The sites where these artworks are displayed are also flexible. In cases where the public display of contentious artworks is possible, they might appear in physical public space, while in cases where this is banned by the state, protestors might turn to digital spaces.

Liu shows that the level of oppressiveness of the political structure does not determine whether protests are possible. Instead, a highly oppressive political structure incentivizes protestors to depart from traditional protest methods. Liu's important contribution is that he vividly shows the internal contraction of an oppressive political structure: it tends to diversify protest method, which makes it harder for the state to manage political resistance. In contrast to $\mathrm{Ci}$, therefore, Liu does not see the oppressive political structure as a limit to political resistance but as an opportunity protestors can exploit to enrich the existing repertoires of contention.

More importantly, Liu's discussion of the tendency of Chinese protests to ally with the central government and utilize the promises of the central government, in order to raise claims against local governments, also challenges a fundamental assumption of Ci's prudential argument: a more democratic and legally rational regime will reduce the number of protests and thus make China more stable. Hence, it is in the interests of the CCP to initiate democratic reforms. 'Paradoxically,' Liu suggests, the CCP's 'continued emphasis on "social stability" and expansion of social rights ... has also made it possible for protestors to blame local authorities' for their misbehaviors (p. 182). The 'dramatic turn to legality as a source of legitimacy, probably beyond the Communist Party of China's anticipation, has spawned widespread rights-based politics from below' (p. 10). Liu's work thus undermined the stability argument for democratization. Protecting the political and legal rights of citizens also means that the cost of organizing and participating in social movement decreases, and a lower cost tends to encourage participation in social movements. Thus, if Liu is correct, then Ci's prudential case for democracy in China, despite its emphasis on the empirical and contextual nature of the argument, is not supported by empirical realities in China.

At the same time, however, it is not clear how democratic and transformative the performative politics of the people described by Liu really is. For Liu, protesting within the boundaries set by the state, rather than 'creating new identity boundaries between "us" and "them", are a creative innovation of the post-1989 era (p. 90). It is true that these self-restricting protests open up new and safer arenas for collective claim-making. Nonetheless, it is no less true that self-restricting protests are unable to challenge the fundamentally undemocratic elements of the regime, which arguably are the root cause of many social and political injustices in China. Buying into the state-imposed boundaries of resistance unavoidably confines the transformative force of people at the local (rather than national) level and stops social

(c) 2020 Springer Nature Limited. 1470-8914 Contemporary Political Theory Vol. 20, S2, S60-S66 
movements in China from being genuinely democratic, as they no longer confront the fundamental problem of a vastly unequal distribution of political power.

In spite of the criticisms that I have raised, each of these fine books makes an important contribution to debates on political legitimacy and political resistance in China. They offer a fresh perspective on the crisis of legitimacy and political instability in China that advocates of the China model have neglected. Both books will be valuable to readers who wish to gain a deeper understanding of these issues.

\section{References}

Bell, D. A. (2015) The China Model: Political Meritocracy and the Limits of Democracy. Princeton, NJ: Princeton University Press.

Butler, J. (2015) Notes Toward a Performative Theory of Assembly. Cambridge, MA: Harvard University Press.

Chatterjee, P. (2004) The Politics of the Governed: Reflections on Popular Politics in Most of the World. New York, NY: Columbia University Press.

Lee, C.K. and Zhang, Y. (2013) The Power of Instability: Unraveling the Microfoundations of Bargained Authoritarianism in China. American Journal of Sociology 118(6): 1475-1508.

Chi Kwok

University of Toronto, Toronto, ON M5S 3G3, Canada

chi3318401@gmail.com

Publisher's Note Springer Nature remains neutral with regard to jurisdictional claims in published maps and institutional affiliations. 